\section{$\underset{\substack{\text { hommes } \\ \text { \& migrations }}}{ }$}

\section{Hommes \& migrations}

Revue française de référence sur les dynamiques

migratoires

$1282 \mid 2009$

Santé et droits des étrangers : réalités et enjeux

\title{
Catherine Wihtol de Wenden, La Globalisation
}

humaine

PUF, 2009, 262 pages, 26 euros

\section{Mustapha Harzoune}

\section{(2) OpenEdition}

Journals

Édition électronique

URL : http://journals.openedition.org/hommesmigrations/481

DOI : 10.4000/hommesmigrations.481

ISSN : 2262-3353

Éditeur

Musée national de l'histoire de l'immigration

Édition imprimée

Date de publication : 1 novembre 2009

Pagination : 204-205

ISSN : 1142-852X

\section{Référence électronique}

Mustapha Harzoune, "Catherine Wihtol de Wenden, La Globalisation humaine », Hommes \& migrations [En ligne], 1282 | 2009, mis en ligne le 29 mai 2013, consulté le 10 décembre 2020. URL : http:// journals.openedition.org/hommesmigrations/481; DOI : https://doi.org/10.4000/hommesmigrations. 481

Ce document a été généré automatiquement le 10 décembre 2020.

Tous droits réservés 


\title{
Catherine Wihtol de Wenden, La Globalisation humaine
}

PUF, 2009, 262 pages, 26 euros

\author{
Mustapha Harzoune
}

\section{RÉFÉRENCE}

Catherine Wihtol de Wenden, La Globalisation humaine, PUF, 2009, 262 pages, 26 euros

1 Dans son discours d'ouverture au Troisième Forum sur les migrations et le développement, le Secrétaire général de l'ONU, Ban Ki-moon, déclarait mercredi 4 novembre que "nous avons du travail devant nous". Comme on dirait en bon français, "on a du pain sur la planche!" Pourquoi ? Entre autres, selon M. Ban Ki-moon, parce que "Nous ne pouvons pas encore dire que le potentiel de développement des migrations internationales soit, aujourd'hui, pleinement réalisé". Et d'ajouter: "nous ne pouvons encore déclarer que les droits des migrants soit pleinement respectés."

Et si l'on devait s'en convaincre un peu plus, il faut lire la dépêche de l'AFP du 9 novembre selon laquelle "le gouvernement libéral-conservateur danois veut multiplier par dix la prime au retour accordée aux immigrés, en leur offrant désormais 100000 couronnes (13 443 euros) pour les inciter à rentrer définitivement dans leur pays." La phrase qui suit indique que "cette décision a été prise dans le cadre d'un accord conclu dimanche soir avec le Parti du peuple danois (PPD, extrême droite), allié parlementaire du gouvernement [...]."

3 Voilà deux illustrations des logiques qui s'affrontent en matière de migrations internationales. Celle qui en fait prévaut depuis plus de trente ans, qui voit dans les migrations internationales un danger dont il faut se prémunir en fermant les frontières et en renvoyant chez eux les "indésirables" et une autre, en émergence depuis quelques années, essentiellement au sein d'institutions internationales, d'ONG et autres cercles intellectuels, dont l'écho commence à porter au-delà des enceintes des conférences internationales et autres ouvrages spécialisés d'universitaires et de journalistes. La 
migration est un droit fondamental, les migrants ont des droits et plutôt que de diaboliser ces migrations internationales, il serait temps d'en saisir les opportunités - en matière de croissance pour les pays d'accueil, de développement pour les pays de départ mais aussi de rencontres et d'échanges démographiques, culturelles, etc. Il serait temps aussi de l'organiser dans une logique où chacun serait gagnant: les pays de départ, d'accueil et le migrant lui-même dans un monde globalisé où les frontières seraient, si ce n'est repoussées, du moins repensées.

Pour faire le point sur les tenants et les aboutissants de ce difficile débat, pour mesurer le terrible échec des politiques étatiques mises en œuvres depuis la fermeture des frontières dans les années soixante-dix, comme pour appréhender l'actualité des réflexions sur l'émergence de ce droit des migrants et d'une gouvernance mondiale des migrations, le livre de Catherine Wihtol de Wenden est un formidable outil. Mieux, ne délaissant pas les enjeux culturels que portent les migrations sur le devenir de chacun et pas seulement des migrants, individuellement et collectivement, il aide à comprendre en quoi l'identité est une notion en permanente construction et reconstruction. Catherine Wihtol de Wenden y expose, clairement - même si l'exhaustivité des chiffres et des faits et quelques répétitions peuvent assécher le propos - les dernières données en matière de mouvements de populations. Si ce n'est pays par pays à tout le moins continent par continent, elle indique également les motifs et les prévisions de ces déplacements, les raisons tant dans les zones d'arrivée (démographiques, économiques, etc.) que dans les zones de départ (économiques, politiques, climatiques, liées à la désertification, au manque d'eau, mais aussi la simple "envie de mobilité comme mode de vie"), les nouvelles formes que prennent ces migrations internationales comme les nouveaux et divers profils des migrants. Enfin, elle montre en quoi et comment cette "globalisation humaine" qui participe du mouvement général de la globalisation ou de la mondialisation fait que " l'État-nation n'est plus la seule communauté de base du système international, ni même l'acteur essentiel". "La mondialisation a contribué à mettre en avant l'individu revendiquant son droit à la mobilité, aux identités multiples et à la citoyenneté plurielle face à l'État-nation. L'immigrationinterroge la souveraineté nationale par la remise en cause du bien fondé du contrôle des frontières."

5 Frontières, droit de migrer, mais aussi droit à résidence, nouvelle citoyenneté (le philosophe Balibar et le sociologue Zygmunt Bauman sont ici convoqués), identité syncrétique, appartenances multiples..., c'est dire à quel point le thème des migrations peut conduire à réviser toutes nos approches sur la marche du monde et le vivre ensemble, comme bousculer bien des paradigmes et certitudes hérités d'un autre siècle. Comme le disait Ban Ki-Moon, il y a du pain sur la planche! Il faut donc se retrousser les manches et user de ce nouvel outil de compréhension... et d'action. Car comme l'écrit l'auteur, l'opinion publique semble encore peu acquise à l'idée de la mondialisation du phénomène migratoire. L'opinion publique, c'est-à-dire aussi les électeurs... 